\title{
$\underline{\mathbf{P}-162}$
}

\section{Isolation of Colletotrichum Gloeosporioides and Antagonist Bacteria from Harumanis Mango and Screening for Biocontrol Activities}

\author{
Falex J. $\mathrm{L}^{1}$, Zainon M. ${ }^{1, *}$ and Fauziah $\mathrm{I}^{2}$ \\ ${ }^{I}$ Faculty of Applied Sciences, Universiti Teknologi MARA Malaysia, 40450 Shah Alam, Selangor Darul Ehsan, \\ Malaysia; ${ }^{2}$ Faculty of Plantation and Agrotechnology, Universiti Teknologi MARA (UiTM), 40450 Shah Alam, \\ Selangor, Malaysia; E-mail: dzainonmn@salam.uitm.edu.my
}

Postharvest disease of mango or commonly known as anthracnose caused by the fungi Colletotrichum gloeosporioides. It is a major pre and postharvest disease on mango, causing direct yield loss in the field and packing plant, quality and marketing issues thereafter. This study were aimed to identify the causal agent of mango anthracnose by isolated the fungus pathogen directly from the host plant and to determine the antagonistic activity and mechanism of potential antagonists bacteria towards C. gloeosporioide. The isolated fungus was grown in vitro on the Potato dextrose agar (PDA) agar and the pure culture was maintained in PDA slants at $28^{\circ} \mathrm{C} \pm 2^{\circ} \mathrm{C}$. Growth rate of the fungus was taken by measuring the diameter $(\mathrm{cm})$ of the colony at the petriplate on the PDA agar daily. This information is vital for finding the potential antagonists against this pathogen. The isolated fungus was also tested for pathogenicity in the laboratory via wound inoculation method. The results were significantly proving the Koch's postulates where $C$. gloeosporioide was found to be the causes of anthracnose disease on Harumanis mango. Preliminary screening of bacteria from healthy mango fruits yielded isolates antagonistic towards C. gloeosporioide, the cause of mango anthracnose. The result from the 24 antagonistic bacteria isolated which were screened by dual culture, 4 isolates of bacteria (BT16, BT09, BT02 and BT05) had high antagonistic activities against C. gloeosporioide of Harumanis mango ranging from $26.25 \%$ to $67.03 \%$. Antagonist bacteria BT16 was strongly inhibited the fungal growth by an average $67.03 \%$, respectively during in vitro screening on PDA medium. Further observations were done under light and scanning electron microscopy revealed that the mode of action of bacteria against the fungus was producing volatile compound which was the antifungal substances. Therefore, in vitro activities of bacteria BT16 against C. gloeosporioide of Harumanis mango suggested that the bacterium can be an effective biological control agent. Further experiments will be done to identify the isolate BT16 and to analyse the extraction of antifungal substances produced by the antagonist bacteria.

Keywords: Colletotrichum gloeosporioides, Antagonist bacteria, Harumanis mango, Pathogenicity, Antifungal substance. 